\title{
PICTOGRAMAS DO GHS E SUA APLICAÇÃO COMO FERRAMENTA DE COMUNICAÇÃO DE PERIGOS PARA
} ESTUDANTES DE GRADUAÇÃO

\author{
Leila K. Uema ${ }^{\text {a }}$ Marcela G. Ribeiro ${ }^{\mathrm{a}, *}$ \\ aFundação Jorge Duprat Figueiredo de Segurança e Medicina do Trabalho, 05409-002 São Paulo - SP, Brasil
}

Recebido em 04/08/2016; aceito em 06/12/2016; publicado na web em 10/02/2017

\begin{abstract}
GHS PICTOGRAMS AS HAZARD COMMUNICATION TOOL FOR UNDEGRADUATE STUDENTS. Regularly, teaching laboratories use chemicals hazardous to health. Students must be aware of such hazards, to safely perform didactic experiments. The Globally Harmonized System of Classification and Labelling of Chemicals (GHS) is a hazard communication tool designed to harmonize the classification with a standardized labeling system worldwide. This work aimed at investigating whether undergraduate students correctly identify the hazards associated with a series of chemicals handled during practical laboratory classes. A questionnaire was administered to the students using the hazard classification established by the GHS as reference. They had to match each chemical with one or more pictograms and hazard classes. Statistical tests were performed to correlate the association between right answers and background items, such as having contact with chemicals during earlier classes, having contact with chemical labels at work or having received training courses in hazard communication. The overall assessment showed that students do not recognize GHS pictograms, especially those representing health hazards and thus, they were not aware of the hazards they were exposed to. Many are the reasons for that. At last, strategies to embed health and safety practices into formal education are needed to strengthen the prevention culture in such a learning environment.
\end{abstract}

Keywords: hazard communication; GHS, pictograms; undergraduate students.

\section{INTRODUÇÃO}

As ferramentas de comunicação exercem papel de fundamental importância no processo de reconhecimento e identificação de perigos decorrentes da exposição aos agentes químicos, uma vez que são geralmente a fonte mais direta de informação. ${ }^{1-3}$ Nesse contexto, entende-se por ferramenta de comunicação um conjunto padronizado de símbolos, palavras e frases capazes de fornecer de maneira simples, clara e objetiva as informações relativas aos perigos dos produtos químicos.

O Sistema Globalmente Harmonizado de Classificação e Rotulagem de Produtos Químicos (GHS) é uma abordagem que traz orientações para a comunicação de perigos dos produtos químicos, entre outras. ${ }^{4}$ Em linhas gerais, o GHS conceitua os perigos físicos, à saúde e ao meio ambiente, e estabelece critérios uniformes para a classificação e a comunicação da informação sobre os mesmos por meio de palavras de advertência, frases de perigo, frases de precaução e pictogramas padronizados, a serem utilizados mundialmente nos rótulos e nas fichas de informação de segurança de produtos químicos (FISPQs).

As palavras de sinalização indicam o grau de severidade do perigo e alertam o usuário sobre os danos potenciais provenientes da exposição ao produto químico. A palavra perigo (em inglês, danger) indica maiores níveis de severidade e a palavra cuidado/atenção (em inglês, warning), níveis menores de severidade.

As frases de perigo descrevem a natureza do perigo como, por exemplo, "líquido e vapor altamente inflamável". São representadas por um código iniciado pela letra " $\mathrm{H}$ " (do inglês, hazard) e uma sequência numérica de três algarismos. As frases de precaução, por sua vez, descrevem medidas a serem tomadas para minimizar ou prevenir efeitos adversos resultantes da exposição aos produtos perigosos oriundos da armazenagem ou da manipulação inadequada dos mesmos. Também são representadas por um código, que neste

*e-mail: marcela.ribeiro@fundacentro.gov.br caso inicia-se com a letra "P" (do inglês, precautionary) seguida por uma sequência numérica de três algarismos. Os códigos das frases de perigo e precaução não devem ser utilizados em substituição aos respectivos textos nos rótulos e nas FISPQs.

Já um pictograma do GHS refere-se a um conjunto de elementos gráficos, incluindo um símbolo, que representa a classe de perigo associada ao produto, e uma borda. Tais elementos são padronizados em forma e cores. O pictograma deve ter forma quadrada, o símbolo deve ser preto, o fundo branco e a borda vermelha. O GHS estabelece nove pictogramas distintos associados às classes de perigos físicos, à saúde e ao meio ambiente.

O Purple Book é o manual oficial da Organização das Nações Unidas (ONU) para o GHS. Foi publicado em 2003 e, desde então, novas revisões são publicadas a cada dois anos. ${ }^{4}$

No Brasil, o primeiro marco importante em direção à regulamentação da classificação e rotulagem de produtos químicos foi dado em 1996, com a ratificação da Convenção 170 da Organização Internacional do Trabalho $(\mathrm{OIT})^{5}$ e, dois anos mais tarde, com a subsequente promulgação do Decreto 2657, de 03 de Julho de $1998 .{ }^{6}$ Em 2009, a Associação Brasileira de Normas Técnicas (ABNT) publicou a primeira edição da norma NBR 14725: "Produtos químicos - Informações sobre segurança, saúde e meio ambiente", ${ }^{7}$ com o objetivo de fornecer diretrizes para a implantação da Convenção 170 e das disposições do GHS no país. Outra regulamentação importante foi estabelecida pelo então Ministério do Trabalho e Emprego (atual Ministério do Trabalho) com a publicação, em 2011, da revisão da Norma Regulamentadora 26 (NR 26), ${ }^{8}$ que passou a incorporar as bases do GHS para classificação, rotulagem e ficha de informações sobre segurança, como exigência para o trabalho com produtos químicos.

Considerando que a adoção do GHS é obrigatoriedade legal no Brasil, sua implementação nos diversos ambientes onde produtos químicos são manipulados, armazenados ou transportados, sejam eles indústrias, instituições de ensino ou pesquisa, requer a familiaridade dos usuários com os elementos de comunicação de perigos preconizados pelo sistema. Dentre esses diversos usuários 
estão estudantes, professores e técnicos de laboratórios de ensino e pesquisa das universidades.

Apesar do exposto, diversos estudos evidenciam a falta de familiaridade desses usuários, especialmente de estudantes, com os elementos de comunicação de perigos e enfatizam a necessidade de se repensar a maneira como os aspectos relativos à segurança química em laboratório são abordados nos cursos de graduação para que contribuam de forma assertiva para o reconhecimento e a identificação dos perigos.9-13

Algumas práticas têm sido sugeridas para aumentar a familiaridade dos estudantes com os elementos de comunicação de perigos dos produtos químicos como, por exemplo, o envolvimento direto dos estudantes nos procedimentos de rotulagem e armazenamento dos reagentes utilizados nas aulas de laboratório; ${ }^{10}$ a exposição dos pictogramas com os símbolos de perigo nos laboratórios didáticos $;{ }^{13}$ a viabilização de vivências práticas em indústrias reais e a integração dos conteúdos, já que a segurança química depende de interações complexas que não conseguem ser devidamente compreendidas com a metodologia tradicional geralmente empregada nos cursos universitários, os quais são bons em ensinar conhecimentos específicos e isolados, mas não colocam aos estudantes desafios que permitam estabelecer conexões entre esses conhecimentos para resolver problemas reais de segurança. ${ }^{14}$

No Brasil, existem poucos estudos relacionados à implementação do GHS nos ambientes de pesquisa e ensino; ${ }^{15,16}$ nenhum com o objetivo de investigar a familiaridade de estudantes com os elementos de comunicação de perigos previstos na legislação e dispostos nos rótulos e FISPQs.

Diante da importância da comunicação de perigos nos processos de prevenção de riscos e da falta de dados relativos ao alcance dos elementos de comunicação nos ambientes de ensino universitário, este trabalho pretendeu contribuir para um diagnóstico preliminar do reconhecimento de perigos dos produtos químicos por estudantes de graduação em Química, tendo como base os pictogramas do GHS. O trabalho pretendeu, ainda, suscitar novas discussões sobre a importância da inserção do tema 'segurança química' ao longo da formação universitária, assim como sobre as estratégias a serem utilizadas para a abordagem sobre o tema.

\section{MATERIAIS E MÉTODOS}

O estudo, de natureza exploratória, com abordagem predominantemente quantitativa e de corte transversal, foi realizado com estudantes de graduação em química de uma universidade do estado de São Paulo. Para o propósito deste estudo de caso, aplicou-se um questionário a 248 estudantes que, na ocasião da pesquisa, cursavam quatro semestres distintos e não consecutivos $\left(2^{\circ}, 4^{\circ}, 6^{\circ}\right.$ e $\left.8^{\circ}\right)$, do referido curso de graduação.

O questionário foi aplicado no próprio ambiente acadêmico, em sala de aula ou laboratório didático, antes do início das atividades didáticas. As substâncias que compuseram o questionário (Tabela 1) foram selecionadas a partir da análise dos protocolos de aulas experimentais.

Os estudantes receberam a 'Parte 1' do questionário, que apresentava uma lista de 20 substâncias químicas (Tabela 1), cada uma das quais os estudantes deveriam marcar como previamente manipuladas ou não por eles nas aulas da graduação. Havia ainda uma tabela a ser preenchida, relacionando cada substância com a(s) respectiva(s) classe(s) de perigo descrita(s) e codificada(s) na Tabela 2. Finalizada esta etapa, os estudantes foram orientados a guardar a 'Parte 1 ' dentro de um envelope e só então receberam a 'Parte 2' que continha outra tabela para que associassem cada substância ao(s) respectivo(s) pictograma(s), conforme codificação apresentada na Tabela 2. Ambas as
Tabela 1. Substâncias químicas avaliadas

\begin{tabular}{cc}
\hline Substância química & Substância química \\
\hline Acetato de etila & Hidróxido de amônio (28\%) \\
Ácido clorídrico (37\%) & Metanol \\
Ácido sulfúrico (98\%) & Nitrato de prata \\
Álcool benzílico & Perclorato de sódio \\
Atrazina & Peróxido de hidrogênio (30\%) \\
Benzaldeído & Sulfato de sódio anidro \\
Clorofórmio & Tetracloreto de carbono \\
Dicromato de potássio & Tiocianato de sódio \\
Hexano & Trimetilamina \\
Hidróxido de sódio & Tolueno \\
\hline
\end{tabular}

associações deveriam ser realizadas considerando as substâncias na forma como são encontradas no seu frasco original, antes de serem diluídas, dissolvidas ou misturadas.

Os estudantes foram alertados para o fato de uma mesma substância poder estar associada a mais de uma classe de perigo e a mais de um pictograma. Foram também orientados a preencher a linha correspondente ao produto com a sigla NC (não conheço) em duas situações distintas: (i) conhecer o perigo associado ao produto químico, mas não conhecer o pictograma que o representa; e (ii) não conhecer o perigo associado a algum produto listado e não poder associá-lo a nenhuma das classes de perigos da Tabela correspondente (Tabela 2). Não houve tempo para discussão ou consulta prévia a nenhuma fonte de informação adicional.

A divisão em duas partes distintas teve o objetivo de garantir que a associação do pictograma à substância química não seria influenciada pela descrição das classes de perigo presente na parte anterior, uma vez que se pretendia verificar o reconhecimento do pictograma sem nenhum recurso textual explicativo.

Os pictogramas do GHS associados às suas respectivas classes de perigo, bem como os códigos utilizados para fins de preenchimento do questionário, encontram-se descritos na Tabela 2. Cabe ressaltar que, no questionário, as classes de perigo e os pictogramas foram apresentados em tabelas distintas e em momentos distintos, conforme descrito acima. As associações entre cada substância e seu(s) respectivos(s) pictograma(s)/classe(s) de perigo, conforme classificação à época da realização desse estudo, encontram-se descritas na Tabela 1S (Material suplementar).

Os resultados obtidos com o questionário foram analisados para fornecer a frequência relativa de associação, pelos estudantes, das classes e pictogramas de perigo a cada substância química da lista apresentada. Analisou-se também a frequência relativa de acertos pelos estudantes das classes e pictogramas associados a cada substância. E por fim, investigou-se a existência de associação estatisticamente significativa entre a frequência relativa de acertos dos pictogramas e: (i) o fato do estudante já ter manipulado a substância no curso; (ii) o fato do estudante já ter trabalhado com produtos químicos fora da graduação; e (iii) o tempo de graduação (o semestre em curso).

Para a análise da frequência de associação (independente de estar correta ou incorreta), os dados foram tabulados atribuindo-se o valor "1" (um) para as classes de perigo e pictogramas que os estudantes associaram a cada substância química da lista e o valor "0" (zero) para as classes de perigo e pictogramas que os estudantes não associaram às respectivas substâncias.

Para determinar a frequência de respostas corretas, os dados foram tabulados atribuindo-se o valor "1" (um) para as classes de perigo e pictogramas que os estudantes acertaram nas respostas para cada substância química da lista e o valor " 0 " (zero) para as classes de perigo e pictogramas que os estudantes erraram nas respostas.

Para verificação de existência de associação estatisticamente 
Tabela 2. Classes de perigo associadas aos seus respectivos pictogramas conforme classificação do $\mathrm{GHS}^{4}$ e $\mathrm{ABNT}^{7}$

\begin{tabular}{|c|c|c|c|}
\hline \multicolumn{2}{|c|}{ Parte 1 do questionário ${ }^{\mathrm{a}}$} & \multicolumn{2}{|c|}{ Parte 2 do questionário ${ }^{\mathrm{b}}$} \\
\hline $\begin{array}{l}\text { Código das } \\
\text { classes de } \\
\text { perigo }^{c}\end{array}$ & Classe de Perigo & Pictograma & $\begin{array}{l}\text { Código dos } \\
\text { Pictogramas }^{\mathrm{d}} \\
\text { Descrição }\end{array}$ \\
\hline $\mathrm{CP} 1$ & Oxidante & & $\begin{array}{c}\text { P6 } \\
\text { Chama sobre } \\
\text { círculo }\end{array}$ \\
\hline $\mathrm{CP} 2$ & $\begin{array}{l}\text { Inflamável; Auto-reativo; } \\
\text { Pirofórico; Auto-aquecimen- } \\
\text { to; Emite gás inflamável; } \\
\text { Peróxido orgânico }\end{array}$ & & $\begin{array}{c}\text { P1 } \\
\text { Chama }\end{array}$ \\
\hline $\mathrm{CP} 3$ & $\begin{array}{l}\text { Explosivo; Auto-reativo; } \\
\text { Peróxido orgânico }\end{array}$ & & $\begin{array}{c}\text { P9 } \\
\text { Bomba explo- } \\
\text { dindo } \\
\end{array}$ \\
\hline $\mathrm{CP} 4$ & Tóxico agudo (severo) & & $\begin{array}{c}\mathrm{P} 2 \\
\text { Caveira e ossos } \\
\text { cruzados } \\
\end{array}$ \\
\hline CP5 & $\begin{array}{l}\text { Corrosivo à pele; Causa danos } \\
\text { severos aos olhos; Corrosivo } \\
\text { aos metais }\end{array}$ & & $\begin{array}{c}\text { P5 } \\
\text { Corrosão }\end{array}$ \\
\hline CP6 & Gás sob pressão & & $\begin{array}{c}\mathrm{P} 3 \\
\text { Cilindro de gás }\end{array}$ \\
\hline $\mathrm{CP} 7$ & $\begin{array}{l}\text { Carcinogênico; Sensibili- } \\
\text { zante respiratório; Tóxico } \\
\text { reprodutivo; Tóxico a órgão } \\
\text { alvo específico (exposições } \\
\text { repetidas); Mutagênico a cé- } \\
\text { lulas germinativas; Perigoso } \\
\text { por aspiração }\end{array}$ & & $\begin{array}{l}\text { P7 } \\
\text { Perigo à saúde }\end{array}$ \\
\hline CP8 & $\begin{array}{l}\text { Tóxico à vida aquática (agu- } \\
\text { do); Tóxico à vida aquática } \\
\text { (crônico) }\end{array}$ & & $\begin{array}{c}\text { P8 } \\
\text { Meio Ambiente }\end{array}$ \\
\hline $\mathrm{CP9}$ & $\begin{array}{l}\text { Irritação da pele e dos olhos; } \\
\text { Sensibilizante da pele; Tóxico } \\
\text { a órgão alvo específico (única } \\
\text { exposição); Tóxico agudo } \\
\text { (prejudicial); Prejudicial à } \\
\text { camada de ozônio }\end{array}$ & & $\begin{array}{c}\text { P4 } \\
\text { Ponto de excla- } \\
\text { mação }\end{array}$ \\
\hline SNP & Substância não perigosa & $\begin{array}{l}\text { Sem } \\
\text { pictograma } \\
\text { associado }\end{array}$ & SNP \\
\hline
\end{tabular}

${ }^{a}$ Relação das classes de perigo e respectiva codificação. ${ }^{\text {b}}$ Relação dos pictogramas de perigo e respectiva codificação. ${ }^{c, d}$ Código da autora para fins de aplicação do questionário.

significativa entre a frequência relativa de acertos dos pictogramas e os fatores (i), (ii) e (iii) mencionados anteriormente considerou-se que as variáveis assim configuradas são qualitativas e o teste não paramétrico do $\chi^{2}$ de Pearson é indicado para verificação de dependência entre duas ou mais amostras com variáveis deste tipo. ${ }^{17}$

$\mathrm{Na}$ análise dos resultados do teste $\chi^{2}$ estabeleceu-se o nível confiança $\alpha \leq 0,05$. Assim, para a verificação de associação com as variáveis (i) e (ii), utilizou-se o software Epi Info ${ }^{\mathrm{TM}} 7$, com uma tabela de entrada de dados $2 \times 2$, definindo o grau de liberdade $=1 \mathrm{e}$ $\chi^{2}$ crítico $\left(\chi^{2 \mathrm{c}}\right)=3,841$. Para a verificação de associação com a variável (iii), utilizou-se o software OpenEpi, com uma tabela de entrada de dados 4 × 2 definindo o grau de liberdade $=3$, obtendo-se $\chi^{2 \mathrm{c}}=$ 7,815 . Em todos os casos, considerou-se associação estatisticamente significativa quando $\alpha \leq 0,05$ e $\chi^{2}>\chi^{2 \mathrm{c}}$.

Os dados para classificação e rotulagem disponibilizados pela Agência Europeia de Produtos Químicos (em inglês, European
Chemicals Agency - ECHA) ${ }^{18}$ foram utilizados como referência nesse trabalho. A ECHA alimenta e divulga a base de dados oficial da Comunidade Europeia, ${ }^{19}$ que identifica as classes e pictogramas de perigos preconizado pelo GHS para uma lista de produtos registrados e reconhecidos como perigosos. Trata-se da base mais completa e confiável para consulta. O acesso é gratuito e os dados atualizados encontram-se disponíveis para download na forma de infocards. ${ }^{20}$ Para acessar os infocards deve-se acessar o site da ECHA e clicar na aba "Information on chemicals". Nessa página, preencher o campo em branco da ferramenta de busca "Search for chemicals", com o nome da substância em inglês. Na lista fornecida, ao clicar no nome da substância abre-se o infocard e obtém-se a informação em "Hazard classification and labelling". É importante ressaltar que muitas substâncias químicas são comercializadas na forma de soluções aquosas diluídas ou misturas e a classificação de uma mesma substância pode variar em função de sua concentração final, seja na mistura ou decorrente da diluição em água. Na página da ECHA na internet é possível consultar os cortes de concentração para a classificação das substâncias químicas quando presentes em misturas ou diluídas em água. ${ }^{7,21}$ Cabe ressaltar ainda que o sistema de classificação é dinâmico e as classificações podem sofrer alterações em função de revisões periódicas. Em caso de dúvidas, a sugestão é sempre buscar a resposta na fonte mais atualizada. ${ }^{7,21}$

\section{RESULTADOS E DISCUSSÃO}

A maioria dos estudantes tinha, na ocasião da pesquisa, entre 18 e 23 anos (74\%) e cursava o $2^{\circ}$ semestre do curso de Química (36\%). A proporção de estudantes que respondeu já ter trabalhado com produtos químicos fora da graduação foi de $49,2 \%$ e a que respondeu que não, $50,8 \%$.

A Tabela 3 mostra que, embora a maioria dos estudantes considere o rótulo dos produtos químicos uma importante fonte de informação de perigos $(81,1 \%)$, a maior parte também respondeu que não utiliza o rótulo para este fim $(66,3 \%)$, principalmente porque usa outra fonte de informação $(56,1 \%)$ ou porque não tem acesso ao rótulo dos produtos químicos $(33,7 \%)$.

Em geral, a frequência relativa de acertos pelos estudantes foi maior para as classes de perigo do que para os pictogramas (Figura 1).

Esses resultados sugerem que os estudantes algumas vezes até reconhecem as classes de perigo relacionadas aos produtos químicos, mas não conhecem os pictogramas que representam essas classes. A dificuldade em interpretar corretamente os pictogramas de perigo já foi relatada em pesquisas anteriores com estudantes ${ }^{10,11,13}$ e com trabalhadores e consumidores em geral. ${ }^{22-24}$

A frequência relativa de respostas corretas para os pictogramas que representam perigos físicos (inflamável: P1; corrosivo: P5; oxidante: P6 - Tabela 2) foi maior do que para os pictogramas que representam perigos à saúde (tóxico agudo severo: P2; tóxico agudo prejudicial: P4; tóxico crônico: P7 - Tabela 2), como mostra a Figura 2.

Os pictogramas P4 e P7 (Tabela 2), que representam perigos à saúde são símbolos introduzidos pelo GHS, e são menos familiares aos estudantes quando comparados aos pictogramas que representam produtos inflamáveis, corrosivos ou oxidantes, cujos símbolos são semelhantes aos utilizados em outros sistemas de classificação de perigos como, por exemplo, o de transporte de produtos perigosos. Além disso, um mesmo pictograma do GHS abrange diferentes tipos de danos à saúde, o que pode contribuir para a dificuldade de interpretação desses pictogramas. Boelhouwer et al., ${ }^{23} \mathrm{em}$ estudo que avaliou a importância da inclusão dos pictogramas do GHS nos rótulos e fichas de segurança para a compreensão dos perigos de produtos químicos, sugerem que o baixo índice de reconhecimento 
Tabela 3. Uso das informações dos rótulos dos produtos químicos como fonte de informações de perigo

\begin{tabular}{|c|c|c|}
\hline $\begin{array}{l}\text { Grau de importância que atribui ao rótulo } \\
\text { como fonte de informação de perigo }\end{array}$ & $\begin{array}{c}\text { Frequência } \\
\text { absoluta }\end{array}$ & $\begin{array}{l}\text { Frequência } \\
\text { relativa }(\%)\end{array}$ \\
\hline 1. Muito importante & 201 & 81,1 \\
\hline 2. Importante & 44 & 17,7 \\
\hline 3. Pouco importante & 2 & 0,8 \\
\hline 4. Não respondeu & 1 & 0,4 \\
\hline Total & 248 & $100,0 \%$ \\
\hline $\begin{array}{l}\text { Usa o rótulo como fonte de informação de } \\
\text { perigo }\end{array}$ & $\begin{array}{c}\text { Frequência } \\
\text { absoluta }\end{array}$ & $\begin{array}{r}\text { Frequência } \\
\text { relativa }(\%)\end{array}$ \\
\hline 1. Sim & 90 & 36,3 \\
\hline 2. Não & 157 & 66,3 \\
\hline 3. Não respondeu & 1 & 0,4 \\
\hline Total & 248 & $100,0 \%$ \\
\hline $\begin{array}{l}\text { Porque não utiliza o rótulo como fonte de } \\
\text { informação de perigo }\end{array}$ & $\begin{array}{c}\text { Frequência } \\
\text { absoluta }\end{array}$ & $\begin{array}{l}\text { Frequência } \\
\text { relativa }(\%)\end{array}$ \\
\hline 1. Não tem acesso ao rótulo & 53 & 33,7 \\
\hline $\begin{array}{l}\text { 2. Não considera o rótulo importante como } \\
\text { fonte de informação de perigo }\end{array}$ & 0 & 0 \\
\hline 3. Não entende as informações do rótulo & 3 & 1,9 \\
\hline $\begin{array}{l}\text { 4. Obtém as informações de perigo de outra } \\
\text { fonte }\end{array}$ & 88 & 56,1 \\
\hline 5. Nenhuma das respostas acima & 11 & 7,0 \\
\hline 6. Não respondeu & 2 & 1,3 \\
\hline Total & 157 & $100,0 \%$ \\
\hline
\end{tabular}

do pictograma que representa os perigos crônicos à saúde do GHS (P7, Tabela 2) pode estar relacionado à polissemia do símbolo empregado para identificar diversos danos: sensibilizante respiratório, mutagênico, carcinogênico, tóxico ao sistema reprodutivo, tóxico à órgãos específicos e perigosos por aspiração. ${ }^{23} \mathrm{O}$ anexo 6 do GHS fornece orientações para a aplicação de testes de compreensibilidade dos elementos de comunicação de perigos que utiliza, dentre eles os pictogramas de perigo. ${ }^{25}$ Esses testes são particularmente importantes para os pictogramas que foram introduzidos por esse sistema.

Observou-se também que os estudantes confundiram os pictogramas que representam os perigos de produtos inflamáveis ( $\mathrm{P} 1$, Tabela 2) e oxidantes (P6, Tabela 2). O gráfico da Figura 3 mostra os pictogramas que os estudantes associaram ao peróxido de hidrogênio, destacando os pictogramas que realmente indicam os perigos desta substância.

Embora o peróxido de hidrogênio não seja um produto inflamável e nem oxidante, muitos estudantes associaram os pictogramas P1 e P6 (Tabela 2) a esta substância. Uma possível explicação para a classificação desta substância como oxidante pelos estudantes é que eles levaram em consideração as propriedades químicas do peróxido de hidrogênio e não o perigo íntrinseco da substância comercial, a partir da qual são preparadas as diluições a serem utilizadas nas aulas, cuja concentração é de $30 \%$. A classificação como oxidante deve ser atribuída apenas às soluções desta substância superiores a 50\%. Este é um ponto de atenção que se deve considerar no uso dos elementos de comunicação do GHS: a classificação do perigo de uma mesma substância química pode diferir em função da sua concentração em uma solução ou mistura. Por isso, ressalta-se a importância de consultar na página da ECHA os cortes de concentração para a classificação das substâncias químicas quando em solução aquosa ou misturas. ${ }^{21}$ Em relação à classificação do peróxido de hidrogênio como inflamável pelos estudantes, pode-se inferir que a semelhança entre os símbolos que representam produtos oxidantes (chama sobre círculo - P6) e inflamáveis (chama - P1), pode ter causado confusão entre os dois símbolos. Resultados semelhantes foram relatados anteriormente em estudo realizado no Japão, onde ambos os símbolos foram interpretados como se referindo aos produtos inflamáveis, evidenciando que os participantes daquele estudo não relacionaram o símbolo da chama sobre círculo à propriedade oxidante. ${ }^{22}$

O gráfico da Figura 4 mostra a frequência relativa das indicações pelos estudantes das substâncias como já manipuladas no curso de graduação e o gráfico da Figura 5 apresenta a frequência relativa de respostas corretas dadas pelos estudantes para classes e pictogramas

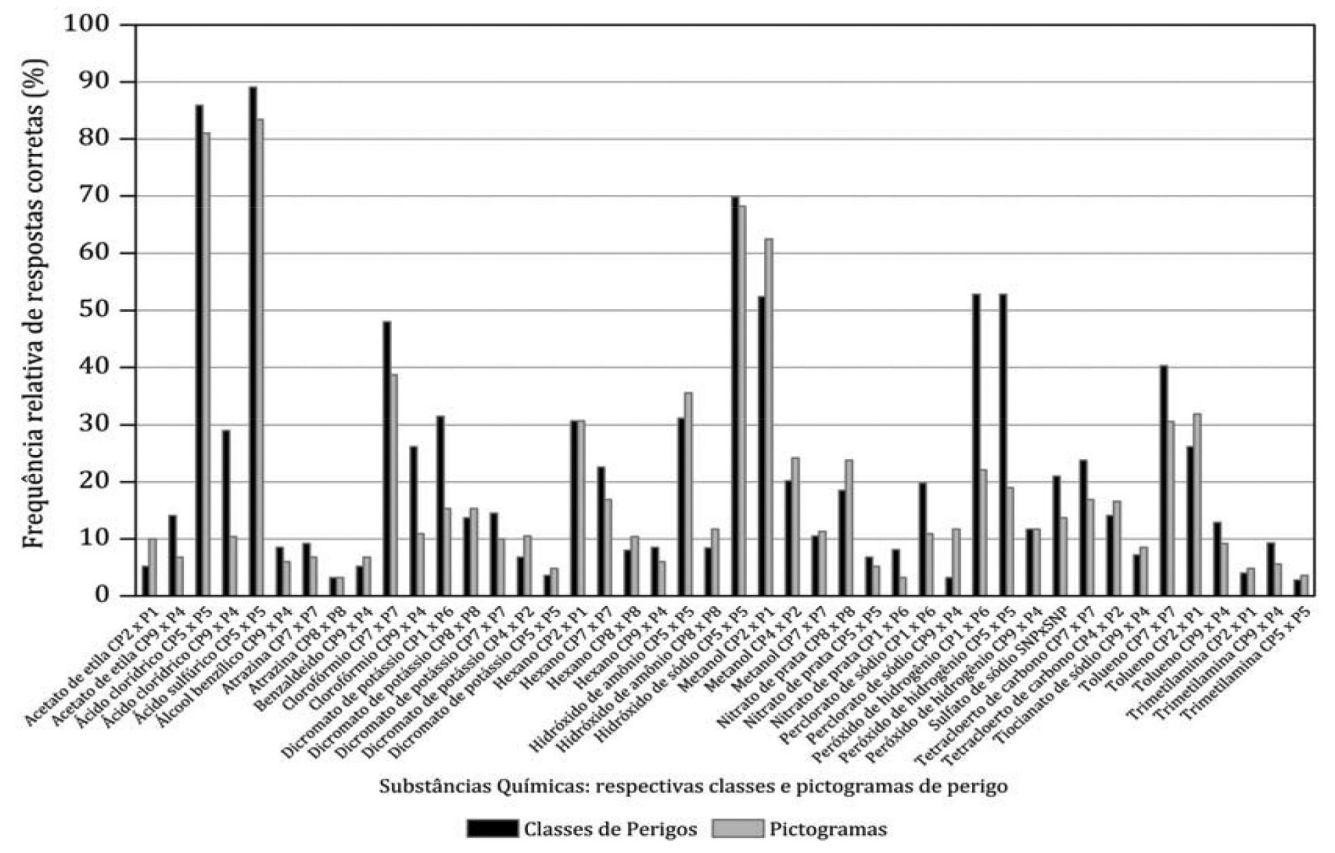

Figura 1. Frequência relativa de respostas corretas: Classes de perigo x pictogramas 


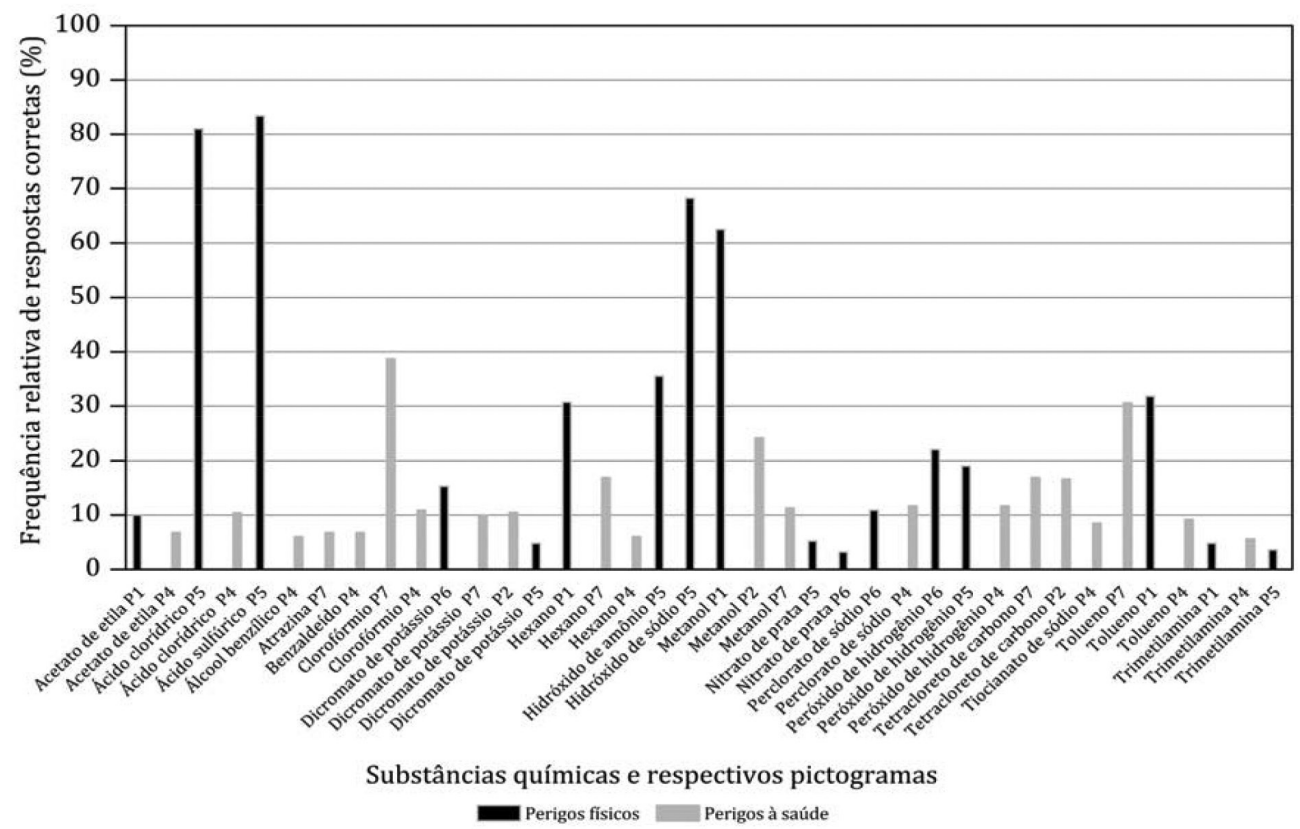

Figura 2. Frequência relativa de respostas corretas: Pictogramas de perigos físicos x Pictogramas de perigos à saúde

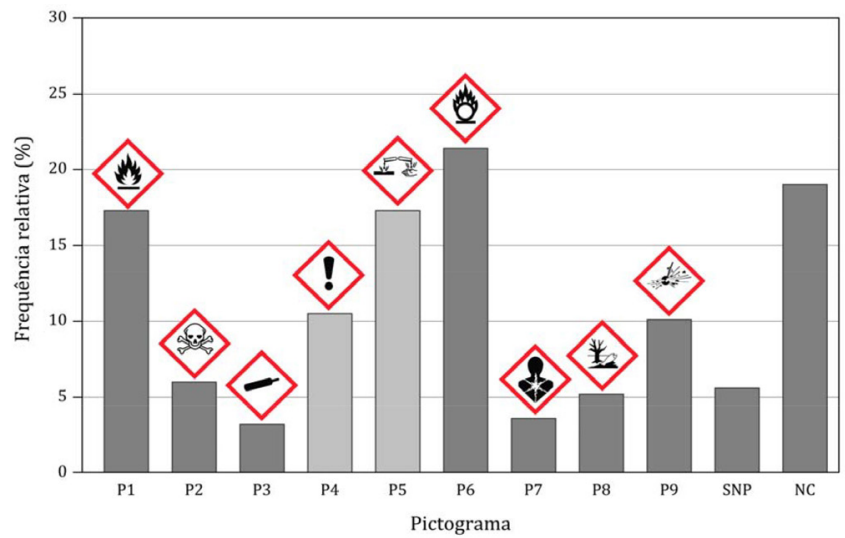

Figura 3. Pictogramas associados ao peróxido de hidrogênio pelos estudantes (em cinza claro estão representadas as barras correspondentes aos pictogramas do peróxido de hidrogênio)

de perigo simultaneamente ( $\mathrm{Fr} 1)$, apenas para classes de perigo $(\mathrm{Fr} 2)$, apenas para pictogramas (Fr3).

A análise dos dados apresentados nas Figuras 4 e 5 permite que se chegue a alguns resultados importantes para a discussão da influência da manipulação das substâncias em aula no adequado reconhecimento dos perigos relativos às mesmas.

O ácido clorídrico, por exemplo, foi uma substância que $100 \%$ dos estudantes indicaram como já manipulada no curso (Figura 4). A Figura 5 mostra que $75 \%$ dos estudantes associaram corretamente a classe (CP5, Tabela 2) e o pictograma (P5, Tabela 2) relativo ao perigo da corrosão. Entretanto, somente 5,6\% dos estudantes associaram corretamente a classe (CP9, Tabela 2) e o pictograma (P4, Tabela 2), que representam os perigos à saúde para esta substância, o que mostra que a maior parte dos estudantes não reconhece os perigos à saúde ocasionados pela exposição ao ácido clorídrico.

O dicromato de potássio está entre as sete substâncias apontadas pelos estudantes com maior frequência como já manipulada no curso (88\%). O gráfico da Figura 6 mostra os pictogramas que os estudantes associaram ao dicromato de potássio, destacando aqueles realmente relacionados a essa substância. Percebe-se que a frequência de respostas corretas de associação desta substância

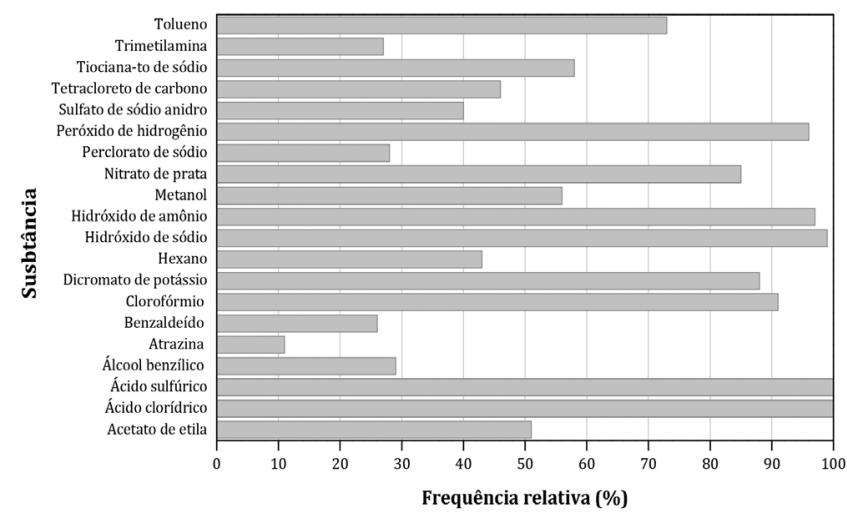

Figura 4. Frequência relativa de indicação pelos estudantes das substâncias como já manipuladas no curso

com os respectivos pictogramas de perigo foi muito baixa. Muitos estudantes responderam não conhecer os pictogramas que deveriam associar a essa substância e alguns ainda classificaram a substância como não perigosa, o que é ainda mais preocupante, pois se trata de uma substância com potencial de causar danos severos à saúde humana, que a maior parte dos estudantes já manipulou no curso sem, aparentemente, ter se dado conta dos perigos intrínsecos do produto.

A manipulação da substância química em aulas prévias no curso não favoreceu o reconhecimento dos pictogramas de perigo da maior parte das substâncias químicas presentes no questionário. A Tabela 4 mostra os resultados do teste $\chi^{2}$ para as situações (dentre as 43 ao todo) que apresentaram associação estatisticamente significativa entre a frequência relativa de respostas corretas dadas pelos estudantes aos pictogramas e o fato de já terem manipulado a substância em aulas anteriores no curso de graduação.

Apenas 10 das 43 situações mostraram associação estatisticamente significativa entre a frequência relativa de acertos e a manipulação prévia da substância. Portanto, para a maioria das situações a manipulação da substância no curso não favoreceu o devido reconhecimento dos pictogramas de perigo. É interessante notar que a associação estatisticamente significativa se deu exatamente para as substâncias indicadas pelos estudantes com menor 


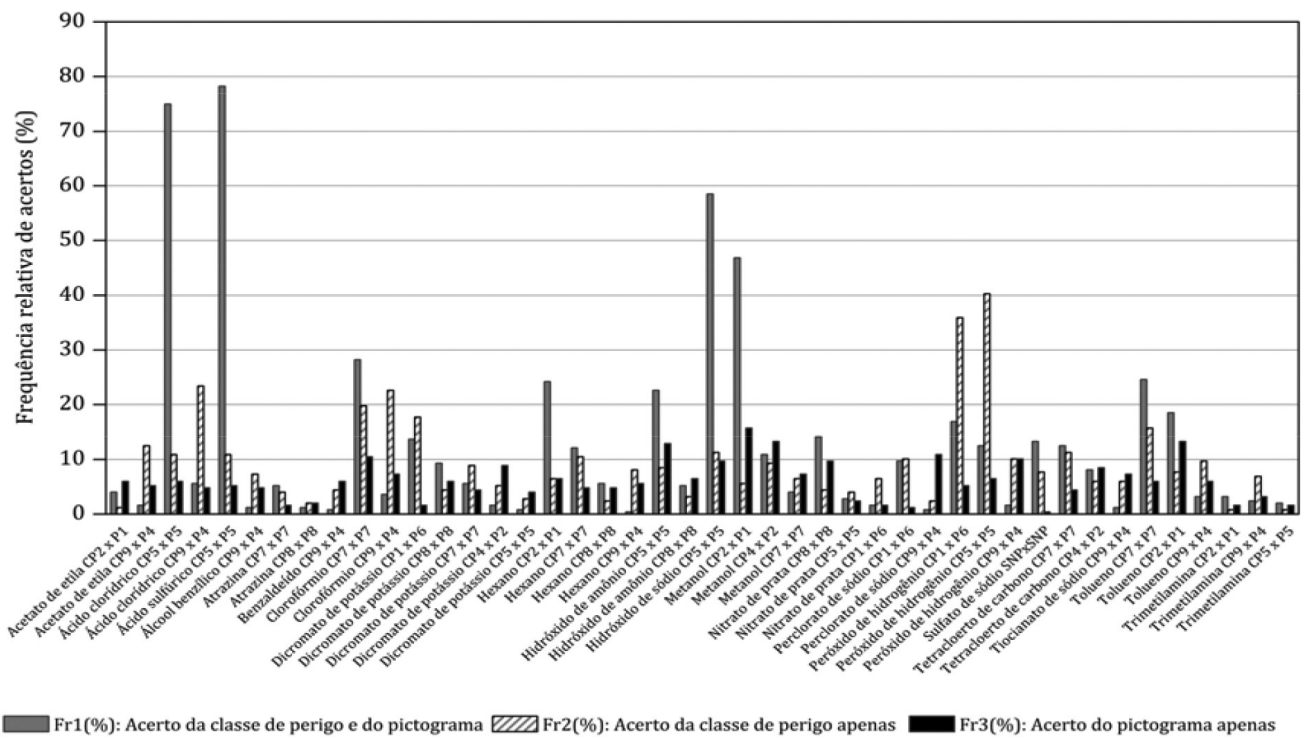

Figura 5. Frequência relativa de respostas corretas

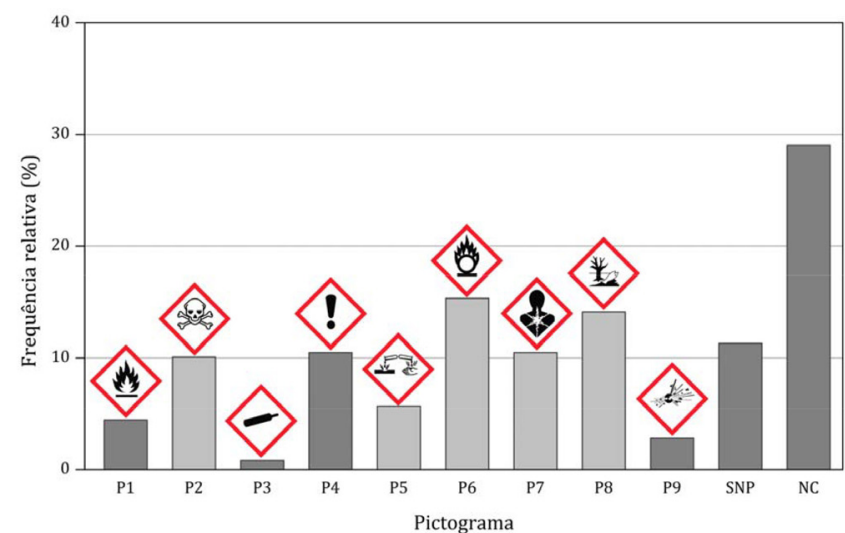

Figura 6. Pictogramas associados ao dicromato de potássio pelos estudantes (em cinza claro estão representadas as barras correspondentes aos pictogramas do dicromato de potássio)

Tabela 4. Associação entre acerto dos pictogramas de perigo e o fato de já ter manipulado a substância química no curso de graduação

\begin{tabular}{lccc}
\hline $\begin{array}{l}\text { Substância } \\
\text { química }\end{array}$ & Pictograma & $\chi^{2}$ & $p$-value \\
\hline Atrazina & P7 & 17,2590 & 0,0000 \\
Atrazina & P8 & 13,0352 & 0,0003 \\
Hexano & P7 & 9,2123 & 0,0024 \\
Metanol & P1 & 7,8289 & 0,0051 \\
Metanol & P2 & 6,2540 & 0,0124 \\
Perclorato de sódio & P4 & 4,7536 & 0,0292 \\
Sulfato de sódio anidro & SNP & 39,1293 & 0,0000 \\
Tiocianato de sódio & P4 & 4,7766 & 0,0288 \\
Tolueno & P1 & 6,5570 & 0,0104 \\
Trimetilamina & P4 & 19,5080 & 0,0000 \\
\hline
\end{tabular}

Associação estatisticamente significativa: Tabela $2 \times 2 ; \mathrm{GL}=1 ; \chi^{2}>3,841 \mathrm{e}$ $p$-value $\leq 0,05$.

frequência como já manipuladas no curso (Figura 5). Daí pode-se inferir que, para algumas substâncias que foram indicadas como já manipuladas por poucos estudantes, talvez por serem peculiares a um dado momento do curso e não serem utilizadas cotidianamente, a manipulação nas aulas foi importante para o correto reconhecimento. É o caso, por exemplo, da atrazina, substância manipulada pelos estudantes somente na disciplina de Química Ambiental, cursada no $8^{\circ}$ semestre.

Algumas práticas observadas durante a realização deste estudo podem explicar tais resultados. Uma delas é a forma pela qual os estudantes são orientados a se preparar para as aulas experimentais. Ao consultar os protocolos de aulas experimentais, observou-se que estes, na maioria das vezes, focam apenas o conteúdo das teorias químicas necessárias para a compreensão das práticas, sem qualquer menção significativa às propriedades de perigo relacionadas às substâncias que serão manipuladas nos experimentos. Além disso, as fontes de consulta utilizadas pelos estudantes para a obtenção das informações de perigo não são as mais adequadas para essa finalidade. Bases de dados como a European Chemicals Agency (ECHA) ${ }^{20}$ ou a ICSC, ${ }^{26}$ mantida Organização Internacional do Trabalho (OIT), não são consideradas. Outra possível razão é a forma como os produtos químicos são apresentados aos estudantes nas aulas práticas. Durante a fase de coleta de dados dessa pesquisa, quando a aplicação dos questionários se deu nos laboratórios didáticos, foi possível observar que a maioria dos produtos químicos é entregue aos estudantes já fracionados sem que sejam preservadas nos rótulos dos frascos secundários as informações dos rótulos originais dos produtos (Figuras 7 A e B). Os frascos originais do produtos são mantidos armazenados em salas anexas aos laboratórios didáticos (Figura 7 C) e são geralmente manipulados apenas pelos técnicos que fazem as preparações dos reagentes para utilização pelos estudantes nas aulas.

O problema em questão não é o fracionamento, que é coerente com a manipulação de pequenas quantidades do produto, mas sim a falta de informações de segurança nos rótulos dispostos nos frascos de fracionamento. Uma vez que os estudantes terão contato somente com esses rótulos, não terão os mesmos como fonte de informação de perigos. Essa observação corrobora as respostas dos estudantes ao indicarem como uma das razões de não utilizarem os rótulos como fonte de informações de perigo, o fato de não terem acesso aos mesmos (Tabela 3).

Razões semelhantes às discutidas anteriormente podem explicar também o resultado de não ter-se verificado associação estatisticamente significativa entre a frequência de acertos dos pictogramas 


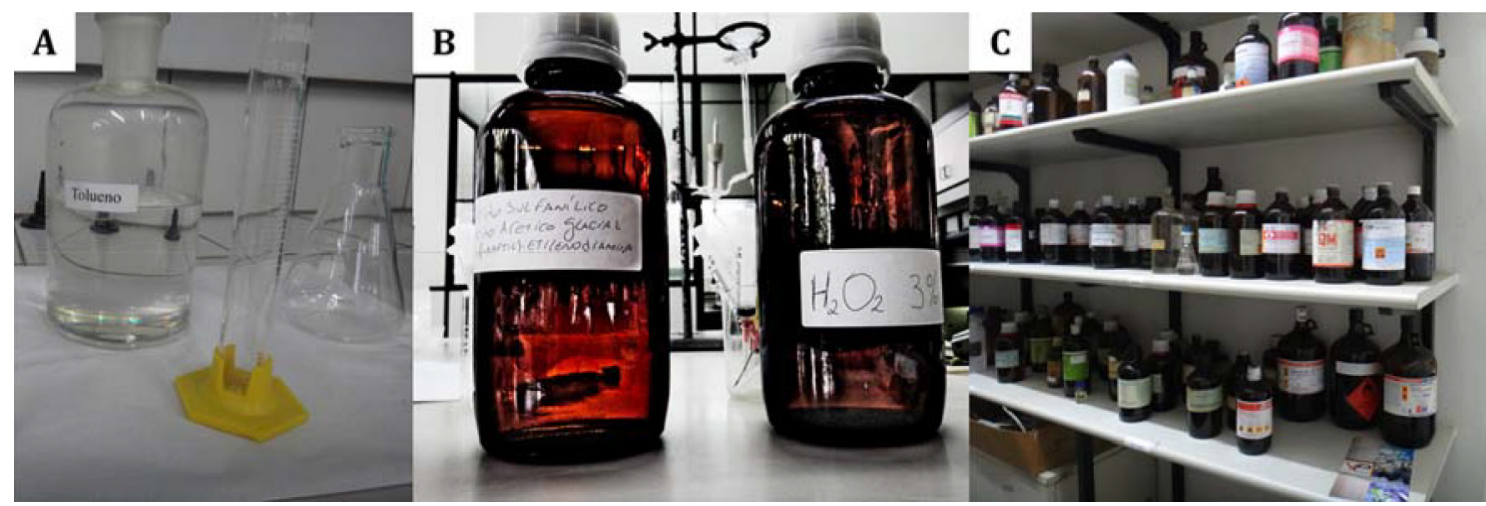

Figura 7. Frascos secundários disponibilizados nas aulas (A)e (B); e armazenamento dos frascos originais (C)

pelos estudantes e o tempo de curso (semestre da graduação) para a maioria das substâncias do questionário.

Somente 16 das 43 situações analisadas mostraram associação estatisticamente significativa entre a frequência de acertos dos pictogramas e o semestre em curso (Tabela 5) e destas apenas 6 mostraram o aumento da frequência de acertos com o aumento do tempo de curso na graduação (Tabela 6).

Esperava-se, inicialmente, que a frequência de acertos pelos estudantes dos últimos semestres fosse maior do que pelos estudantes dos primeiros, uma vez que a carga horária de práticas em laboratórios

Tabela 5. Associação entre acerto dos pictogramas e o semestre em curso na graduação

\begin{tabular}{lcc}
\hline Pictograma associado à substância & $\chi^{2}$ & $p$-value \\
\hline Clorofórmio (P7) & 10,61 & 0,0141 \\
Dicromato de potássio (P6) & 24,63 & 0,0000 \\
Dicromato de potássio (P8) & 12,99 & 0,0047 \\
Hexano (P4) & 80,68 & 0,0000 \\
Hexano (P7) & 18,11 & 0,0004 \\
Hexano (P8) & 20,05 & 0,0002 \\
Hidróxido de amônio (P5) & 12,16 & 0,0068 \\
Metanol (P2) & 22,47 & 0,0000 \\
Metanol (P7) & 9,749 & 0,0208 \\
Perclorato de sódio (P6) & 11,78 & 0,0082 \\
Peróxido de hidrogênio (P6) & 8,738 & 0,0330 \\
Sulfato de sódio (SNP) & 23,87 & 0,0000 \\
Tetracloreto de carbono (P2) & 17,35 & 0,0006 \\
Tetracloreto de carbono (P7) & 28,27 & 0,0000 \\
Tolueno (P1) & 14,84 & 0,0020 \\
Tolueno (P7) & 20,22 & 0,0001 \\
\hline Associaco es & $:$ & $3: \chi^{2}>7,85$
\end{tabular}

Associação estatisticamente significativa: Tabela $4 \times 2 ; \mathrm{GL}=3 ; \chi^{2}>7,815$ e p-value $\leq 0,05$. e o contato com produtos químicos se acumulam ao longo dos anos. Entretanto, não foi o que se observou para a maioria das substâncias apresentadas.

$\mathrm{O}$ fato de o estudante ter trabalhado com produtos químicos fora da graduação contribuiu mais que o tempo de curso para a frequência de acertos dos pictogramas pelos estudantes, embora essa contribuição ainda tenha sido observada para a minoria das situações apresentadas. A Tabela 7 mostra que 17 das 43 situações analisadas evidenciaram associação estatisticamente significativa entre a frequência de acertos dos pictogramas e o fato do estudante já ter trabalhado com produtos químicos fora do curso.

A manipulação de produtos químicos nos ambientes de trabalho é regulamentada por leis trabalhistas, previdenciárias e ambientais e o ambiente laboral está sujeito a controles governamentais e mercadológicos, o que não é tão evidente nos ambientes acadêmicos. Por isso, o fato de trabalhar com produtos químicos fora do curso de graduação deve aumentar o acesso às informações de perigo pelos estudantes, inclusive aos rótulos dos produtos, contribuindo para o maior reconhecimento dos pictogramas de perigo. Hara et al. ${ }^{22}$ analisaram a influência da ocupação profissional com produtos químicos no nível de reconhecimento das informações dos rótulos estabelecidos conforme o GHS e verificaram que os participantes que exerciam atividade laboral relacionada com produtos químicos obtiveram melhor resultado quanto ao acerto dos símbolos dos pictogramas de perigo do que aqueles com outra ocupação profissional.

Vários países possuem dispositivos legais e normativos que têm o objetivo de proteger trabalhadores nos ambientes de trabalho: a Lei de União Europeia (Comissão das Comunidades Europeias, 1992), ${ }^{27}$ a Lei dos Estados Unidos (US Code, 1970), ${ }^{28}$ a Lei Australiana (Instituto de Informação Legal Australasian, 1984), ${ }^{29}$ a Lei das Nações Unidas (Organização Internacional do Trabalho organização, 1981) ${ }^{30}$ entre outros. Entretanto, esses dispositivos normalmente não consideram estudantes e nem contemplam os ambientes acadêmicos. ${ }^{10}$ Karapantsios et al. ${ }^{10}$ discutem a necessidade da criação de leis tão ou mais rígidas como as voltadas aos trabalhadores para proteger os estudantes, não só porque este é um dever ético e legal das universidades, mas também porque os estudantes normalmente

Tabela 6. Frequência relativa de acertos dos pictogramas em função do semestre*

\begin{tabular}{|c|c|c|c|c|c|c|}
\hline $\begin{array}{l}\text { Semestre } \\
\text { (total de alunos) }\end{array}$ & $\begin{array}{l}\text { Clorofórmio } \\
\text { P7 (\%) }\end{array}$ & $\begin{array}{c}\text { Dicromato de potássio } \\
\text { P6 }(\%)\end{array}$ & $\begin{array}{l}\text { Hexano } \\
\text { P7 (\%) }\end{array}$ & $\begin{array}{l}\text { Metanol } \\
\text { P2 (\%) }\end{array}$ & $\begin{array}{l}\text { Metanol } \\
\text { P7 (\%) }\end{array}$ & $\begin{array}{c}\text { Perclorato de sódio } \\
\text { P6 }(\%)\end{array}$ \\
\hline $2^{\circ}$ (89 alunos) & 29,2 & 5,6 & 6,7 & 11,2 & 4,5 & 5,6 \\
\hline $4^{\circ}$ (57 alunos) & 33,3 & 10,5 & 14,0 & 22,8 & 10,5 & 7,0 \\
\hline $6^{\circ}$ (45 alunos) & 44,4 & 15,5 & 20,0 & 24,4 & 13,3 & 11,1 \\
\hline $8^{\circ} / 10^{\circ}$ (57 alunos) & 54,4 & 35,0 & 33,3 & 45,6 & 21,0 & 22,8 \\
\hline
\end{tabular}

*Apenas aquelas substâncias cuja frequência de acertos aumentou com a progressão nos semestres. 
Tabela 7. Substâncias com associação estatisticamente significativa entre acerto dos pictogramas e ter trabalhado com produtos químicos fora do curso de graduação

\begin{tabular}{lccc}
\hline Produto químico & Pictograma & $\chi^{2}$ & $p$-value \\
\hline Acetato de etila & P1 & 5,7860 & 0,0161 \\
Ácido sulfúrico & P5 & 7,8027 & 0,0052 \\
Benzaldeído & P4 & 5,4332 & 0,0197 \\
Dicromato de potássio & P6 & 10,7694 & 0,0010 \\
Dicromato de potássio & P8 & 10,7694 & 0,0001 \\
Hexano & P1 & 10,2368 & 0,0014 \\
Hidróxido de amônio & P5 & 6,6440 & 0,0099 \\
Metanol & P2 & 11,6009 & 0,0007 \\
Metanol & P7 & 6,2436 & 0,0125 \\
Nitrato de prata & P6 & 4,8534 & 0,0276 \\
Perclorato de sódio & P6 & 7,5044 & 0,0061 \\
Peróxido de hidrogênio & P6 & 9,2425 & 0,0023 \\
Sulfato de sódio anidro & SNP & 11,7296 & 0,0006 \\
Tetracloreto de carbono & P2 & 3,9747 & 0,0462 \\
Tetracloreto de carbono & P7 & 9,8305 & 0,0017 \\
Tolueno & P7 & 14,0664 & 0,0002 \\
Trimetilamina & P4 & 5,1236 & 0,0236 \\
\hline Associaço estatisican & & &
\end{tabular}

Associação estatisticamente significativa: Tabela $2 \times 2 ; \mathrm{GL}=1 ; \chi^{2}>3,841 \mathrm{e}$ $p$-value $\leq 0,05$.

têm menos treinamento do que os trabalhadores para lidar com os fatores de risco.

O número de acidentes envolvendo estudantes em instituições acadêmicas é elevado, entretanto, isso nem sempre é percebido, pois normalmente os impactos e prejuízos decorrentes destes acidentes são confinados às próprias instituições onde os eventos aconteceram. ${ }^{31}$

Em 2011 a agência americana CBS (Chemical Safety Board), que investiga acidentes envolvendo produtos químicos, publicou em seu site um vídeo intitulado "Experimenting with dangers", produzido para relatar e discutir acidentes ocorridos em laboratórios de instituições acadêmicas. O vídeo apresenta os resultados das investigações dos acidentes realizadas pelo CBS, com a finalidade de ressaltar a necessidade de as universidades adotarem medidas que criem condições mais seguras para o trabalho nos laboratórios acadêmicos. ${ }^{32}$

O Brasil também possui dispositivos legais e normativos para a proteção dos trabalhadores, mas assim como outros países, carece de regulamentação semelhante para a proteção dos estudantes nos ambientes acadêmicos. Por isso, devem ser tomadas ações no âmbito da própria instituição de ensino e pesquisa para aumentar a conscientização dos estudantes em relação aos perigos potenciais dos laboratórios acadêmicos e da manipulação de produtos químicos.

Nesse sentido, criar estratégias de ensino que aumentem a familiaridade dos estudantes com os elementos de comunicação de perigos do sistema de classificação e rotulagem de produtos químicos vigente no país é fundamental para a segurança dos estudantes.

\section{CONCLUSÕES E RECOMENDAÇÕES}

Os resultados desta pesquisa, realizada com estudantes de graduação em química de uma universidade do estado de São Paulo, indicam que os pictogramas utilizados nos rótulos dos produtos químicos não são eficazes como fonte de informação de perigos para estudantes que manipulam substâncias químicas em aulas de laboratório, principalmente porque a maioria dos estudantes não utiliza os rótulos dos produtos químicos para essa finalidade, e quando utilizam, não identificam corretamente os perigos representados pelos respectivos símbolos, pois a maioria dos estudantes desconhece o significado dos pictogramas, que por sua vez, não são autoexplicativos.

O tempo de curso na universidade não tem contribuído para que os estudantes evoluam na conscientização e no reconhecimento dos perigos, pois as práticas de ensino, da forma como são realizadas hoje, não favorecem a identificação dos perigos pelo contato contínuo e familiarização com esses elementos de comunicação, bem como a consequente avaliação de riscos pelos estudantes. Essas habilidades serão aprendidas somente mais tarde no exercício da profissão, quando deveriam ter feito parte do aprendizado no curso de graduação.

Não é particularidade do curso nem da universidade que foi objeto desta pesquisa o fato de que os assuntos de segurança são tratados num plano secundário em relação às teorias químicas que se pretende ensinar. Contudo, para o desenvolvimento completo das competências do profissional que se está formando, temas relativos à saúde e segurança deveriam estar no mesmo patamar de preocupação que o aprendizado das teorias químicas.

Mais do que criar uma nova disciplina em currículos já carregados de conteúdos, o desafio está em pensar numa estratégia para integrar a segurança química nas atividades pedagógicas já praticadas no curso. ${ }^{33}$ Os estudantes precisam ser expostos à práticas ativas de aprendizagem que permitam que adquiram a expertise de trabalhar com produtos químicos com segurança ao mesmo tempo em que reflexões mais profundas lhes sejam requisitadas para que se conscientizem da sua responsabilidade na preservação de sua saúde e segurança, assim como daqueles que estão ligados às suas atividades acadêmicas.

Envolver os estudantes nos processos de rotulagem de frascos secundários de acordo com o preconizado pelo $\mathrm{GHS}^{4}$ e ABNT; ${ }^{7}$ orientá-los a utilizar fontes adequadas de informação de perigos de produtos químicos para a elaboração destes rótulos, conforme preconizado pelo GHS; solicitar que planejem os roteiros experimentais considerando as boas práticas de segurança desde a escolha dos reagentes, pensando na utilização e também no descarte adequado dos resíduos gerados; estimular a troca de informações sobre os perigos dos produtos químicos entre os estudantes dos diversos semestres, são alguns exemplos de ações que podem contribuir nesse sentido. Sistemas simplificados de rotulagem como o proposto pela Associação das Cooperativas Profissionais e das Seguradoras contra Acidentes de Trabalho da Alemanha (em alemão, Deutsche Gesetzliche Unfallversicherung, DGUV) ${ }^{34}$ podem ser um bom início do ponto de vista didático, mas como descrito por Wallau ${ }^{16}$ não dispensam a aplicação das exigências do GHS.

A gestão dos produtos químicos considerando as diretrizes do GHS é uma obrigatoriedade legal no Brasil ${ }^{7,8}$ e deve ser disseminada para os ambientes de trabalho, incluindo os de pesquisa e de ensino e para todos aqueles que compartilham destes ambientes. A preocupação não é só com o exercício da futura profissão do químico, mas também com a criação da cultura de prevenção nos ambientes acadêmicos que, em sua maioria, carecem de estratégias e ferramentas que permitam a realização do ensino e da pesquisa de forma segura para todos os envolvidos no processo.

\section{MATERIAL SUPLEMENTAR}

Está disponível em http://quimicanova.sbq.org.br, em arquivo pdf, com acesso livre, o seguinte material: Tabela $1 \mathrm{~S}$, na qual podem ser consultadas as associações entre cada substância e seu(s) respectivos(s) pictograma(s)/classe(s) de perigo, conforme classificação à época da realização desse estudo. 


\section{REFERÊNCIAS}

1. Occupational Safety and Health Administration - US Department of Labor; Hazard Communication: Hazard Classification Guidance for Manufactures, Importers, and Employers, https://www.osha.gov/ Publications/OSHA3844.pdf, acessada em janeiro de 2017.

2. https://www.ehs.harvard.edu/programs/hazard-communication, acessada em janeiro de 2017.

3. Plough A.; Krimsky S.; Science, Technology, \& Human Values 1987, 12, 4.

4. UNECE; Globally Harmonized System of Classification and Labelling of Chemicals (GHS), $6^{\text {th }}$ ed., United Nations: New York, 2011, http://www. unece.org/trans/danger/publi/ghs/ghs_rev06/06files_e.html\#c38156, acessada em janeiro de 2017.

5. International Labour Organization; C170 - Chemicals Convention 1990, http://www.ilo.org/dyn/normlex/en/f?p=NORMLEXPUB:12100:0::NO ::P12100_INSTRUMENT_ID:312315, acessada em janeiro de 2017.

6. http://www.planalto.gov.br/CCiVil_03/decreto/D2657.htm, acessada em janeiro de 2017.

7. ABNT, Produtos químicos - Informações sobre segurança e meio ambiente, partes 1-4, Norma Brasileira NBR 14725, Associação Brasileira de Normas Técnicas, ed.; ABNT, Rio de Janeiro: 2012, versão corrigida 2015, página de busca: http://www.abntcatalogo.com. br, procurar a Norma pelo número.

8. Ministério do Trabalho e Emprego, Norma Regulamentadora NR $26-$ Sinalização de Segurança, http://www.mtps.gov.br/images/Documentos/ SST/NR/NR26.pdf, acessada em janeiro de 2017.

9. Su, T. S.; Hsu, I. Y.; Saf. Sci. 2008, 46, 1385.

10. Karapantsios, T. D.; Boutskou, E. I.; Toulipoulou, E.; Mavros, P.; Education for Chemical Engineers 2008, 3, 66.

11. Anilan, B.; Procedia - Social and Behavioral Sciences 2010, 2, 4092.

12. Artdej, R.; Procedia - Social and Behavioral Sciences 2012, 46, 5058.

13. Adane, L.; Abeje, A.; World Appl. Sci. J. 2015, 16, 290.

14. Pitt, M. J.; Chem. Eng. Technol. 2012, 35, 1341.

15. Wallau, W. M.; dos Santos Júnior, J. A.; Quim. Nova 2013, 36, 607.

16. Wallau, W. M.; dos Santos, A. J. R. W. A.; Quim. Nova 2013, 36, 1267.

17. Morettin, P. A.; Bussab, W. O.; Estatística básica, $8^{a}$ ed., Saraiva: São Paulo, 2013

18. http://echa.europa.eu/information-on-chemicals/cl-inventory-database, acessada em janeiro de 2017.

19. http://ec.europa.eu/growth/sectors/chemicals/reach/, acessada em janeiro de 2017.
20. http://echa.europa.eu/documents/10162/22177693/what_is_an_infocard_ en.pdf, acessada em janeiro de 2017.

21. https://echa.europa.eu/information-on-chemicals/cl-inventory-database/-/ discli/details/53297, acessada em janeiro de 2017.

22. Hara, K.; Mori, M.; Ishitake, T.; Kitajima, H.; Sakai, K.; Nakaaki, K.; Jonai, H.; J. Occup. Health 2007, 49, 260.

23. Boelhouwer, E.; Davis, J.; Franco-Watikins, A.; Dorris, N.; Lungu, C.; J. Saf. Res. 2013 46, 145.

24. Dalvie, M. A.; Rother, H-A; London, L.; Saf. Sci. 2014, 61, 51.

25. http://www.unece.org/fileadmin/DAM/trans/danger/publi/ghs/ghs_rev06/ English/09e_annex6.pdf, acessada em janeiro de 2017.

26. http://www.ilo.org/safework/info/publications/WCMS_113134/lang--en/ index.htm, acessada em janeiro de 2017.

27. Commission of the European Communities; Working with Dangerous Products - European Year of Safety and Health Protection at Work, Commission of the European Communities, Office for Official Publications of the European Communities, Luxembourg, 1992, http://bookshop.europa.eu/en/working-with-dangerous-products-pbCENG92001/, acessada em janeiro de 2017.

28. https://www.osha.gov/pls/oshaweb/owasrch.search_form?p_doc_ type=OSHACT, acessada em janeiro de 2017.

29. Australasian Legal Information Institute; Occupational Safety and Health Act 1984, http://www.austlii.edu.au/au/legis/wa/consol_act/ osaha1984273/, acessada em janeiro de 2017.

30. International Labour Organization; C155 - Occupational Safety and Health Convention 1981, http://www.ilo.org/dyn/normlex/en/f?p=100 0:12100:0::NO:12100:P12100_INSTRUMENT_ID:312300, acessada em janeiro de 2017.

31. Meyer, T.; Education for Chemical Engineers 2015, no prelo.

32. http://www.csb.gov/csb-releases-new-video-on-laboratory-safety-at-academic-institutions/, acessada em janeiro de 2017.

33. European Agency for Safety and Health at Work; Mainstreaming occupational safety and health into university education, http://osha.europa. eu/en/publications/reports/mainstream_osh_university_education, acessada em janeiro de 2017.

34. DGUV (ed.) BGI/GUV-I 850-0e: Working Safely in Laboratories Basic Principles and Guidelines, BG RCI, Heidelberg, 2015, http://bgi850-0. vur.jedermann.de/index.jsp, acessada em janeiro de 2017. 